\title{
Sartre, Marx e o Marxismo
}

Jorge Grespan

Universidade de São Paulo

resumo 0 artigo destaca o interesse ainda atual da crítica sartre a na ao marxismode seu tempo na Crítica da razão dialética. Destaca, no entanto, que o alvo desse interesse reside me nos no indivíduo, como quer o humanismo sartreano, do que no evento individual, na singularidade histórica.

palavras-chave Marxismo; história; dialética; ação; humanismo.

"Não ultrapassado"1 me parece também o diagnóstico feito há 50 anos por Sart re em relação ao marxismo e seu tempo, que ainda é o nosso. Exatamente nesses termos ele avaliava o valor e a permanência da teoria de Marx, como a terceira grande matriz filosófica da modernidade, depois da cartesiana e da kantiano-hegeliana. Se, como ele afirma, uma filosofia é mais do que um "método de investigação", é uma "totalização do Saber, (...) Idéia reguladora, arma ofensiva e comunidade de linguagem" (SARTRE, 1986, pp. 10 e 12), ela pertence de modo privilegiado ao tempo que a engendrou. O que pode superar uma filosofia é apenas o movimento real desse mundo cujo "horizonte" ela constitui e que, no caso, ainda não mudou substancialmente desde os tempos definidos por Marx pela alienação do homem. Os pensadores que a continuam e também os que a criticam pertencem ainda a esse mesmo tempo, e são por isso chamados por Sart re de "ideólogos" e não tanto fundadores de filosofia nova. É no contexto desse debate "ideológico" que ele apresenta as suas próprias posições em relação ao marxismo,

Recebido em 12 de maio de 2006. Aceito em 23 de junho de 2006.

doispontos, Curitiba, São Carlos, vol. 3, n. 2, p.159-171, outubro, 2006. 
correções de rota cruciais em relação aos desvios e simplificações operados no século XX.

Neste sentido, ainda nos interessa a crítica de Sartre ao marxismo do seu tempo, pela permanência neste dos cacoetes que sempre ameaçam de novas e antigas deformações. Talvez tenha mudado o motivo da preocupação sartreana: reencontrar o indivíduo, na década de 50, tinha muito a ver com a chamada desestalinização e com a conseqüente ênfase numa leitura humanista de Marx; hoje talvez não fosse tanto o indivíduo, mas o evento individual, a singularidade histórica, também tão defendida por Sartre contra aquele reducionismo que a considerava como o elemento acidental a ser depurado em toda explicação histórica, em favor dos grandes esquemas que remetiam para os quadros gerais, para os universais. Com o pretexto de fazer história, esse marxismo faria muito mais uma sociologia do passado. Mas o específico do trabalho do historiador seria justamente recuperar a singularidade do evento, de suas motivações e condições, como algo irredutível ao universal do saber, para, a partir daí, "situar" esta singularidade através de uma operação de "totalização".

Examinemos mais de perto estas expressões da linguagem existencial do autor - "situação", "totalização" - e a intenção da sua polêmica, em primeiro lugar com os marxistas, e depois, em parte e não assumidamente, com o próprio Marx.

O defeito geral das análises marxistas, até em algumas mais sofisticadas, como a da Revolução Francesa de 1789 por Daniel Guérin, apareceria já de início como sendo a imediatidade da redução das ações políticas a interesses econômicos. Sartre afirma que Girondinos e Montagnards, por exemplo, não podem ser considerados "instrumentos passivos" da sua classe social - os armadores e mercadores de Bordéus no caso dos primeiros, a pequena burguesia, no dos segundos -, pois a política para eles era "um absoluto, um irredutível" (SARTRE, 1986, pp. 44 e 42). Importa evitar a subsunção brutal dos fatos e dos indivíduos históricos a "leis" de movimento consagradas, e estabelecidas em seguida como válidas 'a priori'. Esta subsunção revelaria um afã por conferir ao marxismo o status de ciência dedutiva, que merece de Sartre uma crítica avassaladora: tal marxismo acaba resvalando para o seu oposto, que ele imagina superar, o Idealismo.

Com isso, parece apenas que Sartre pode ser alinhado como mais um dos críticos do teorema marxista 'base/superestrutura', tão debatido em 
boa parte do século XX. Mas uma ressalva fundamental deve ser feita aqui. Ele mesmo afirma que sua crítica vale apenas para os motivos da guerra movida pelos Girondinos em 1792, e não tanto para os políticos de 1793, que teriam, sim, feito a guerra agora em nome dos interesses diretos de sua classe. Ou seja, nem sempre ele acredita errôneo levar em conta o econômico, pois às vezes esse se apresenta imediatamente como motivo das ações políticas ${ }^{2}$. Por isso, Sartre também condena que se procure, inversamente ao "idealismo" de certos marxistas, "determinar de uma vez por todas a natureza e a força das resistências opostas pelos fenômenos da superestrutura às tentativas de redução brutal: isso seria opor um idealismo a outro" (SARTRE, 1986, p. 42). Ou seja, tanto no caso em que se pressupõe a prioridade da base sobre a superestrutura, quanto naquele em que, ao contrário, seria pressuposta uma prioridade da superestrutura em relação à base econômica, teríamos um "idealismo". O erro, portanto, seria considerar em todos os casos, antes de examinar sua peculiaridade histórica, que as forças de um certo tipo ou nível da realidade social sejam determinadas por outras. A crítica de Sartre não visa à relação base-superestrutura em si mesma, e sim à falta de atenção histórica dos que julgam poder afirmar pressupostos teóricos quaisquer, sem considerar suficientemente a realidade.

Mais ainda, os apelos sartreanos para "aprofundar os homens reais", para "passar pela mediação dos homens concretos" (SARTRE, 1986, p. 42 e 43), para considerar de fato a história, não se fazem apenas em nome de um realismo metodológico, de uma crítica ao apriorismo. Eles apre se ntam uma justificativa da relevância do existencialismo para o marxismo, que incorporaria a este último a reflexão sobre a "irredutibilidade de um certo real ao pensamento", sobre a "incomensurabilidade do real e do saber" (SARTRE, 1986, p. 16 e 17), isto é, a reflexão de que a vida concreta sempre tem um caráter de resíduo diante da vida apreendida pela idéia. Sart re enfatiza que, neste sentido, a crítica de Marx a Hegel segue um caminho semelhante ao de Kierkegaard, só que do ponto de vista da "História real" (SARTRE, 1986, p. 17), dos homens reais porque históricos, produtores de sua própria vida.

A qualidade desta crítica de Marx teria até anulado a importância histórica do existencialismo de tipo kierkegaardiano, se o próprio marxismo não tivesse se transformado naquele novo idealismo, ao propor as 
idéias de Marx como ve rdades inquestionáveis por qualquer pesquisa empírica. É no contexto de tal apriorismo que Sart re afirma a tarefa atual do existencialismo: ele "pôde renascer e se manter porque reafirmava a realidade dos homens"; ou ainda, "o objeto do existencialismo pela carência dos marxistas - é o homem singular (...)" (SARTRE, 1986, p. 31 e 121).

Sartre não pretende com isso, porém, modificar os princípios marxistas, e nem mesmo complementá-los. Ele adverte: "Conviria estudar os caracteres concretos sobre a base do movimento econômico, mas sem desconhecer ('méconnaitre') sua especificidade. Assim somente é que podemos visar à totalização. Isso não quer dizer que a condição material (...) seja insuficientemente 'determinante' em relação à atitude considerada. Ou, se se preferir, não há necessidade de acrescentar nenhum outro fator, desde que se estude em todos os níveis a ação recíproca dos fatos que ela engendra através do projeto humano" (SARTRE, 1986, p. 97). Não se trata, portanto, de introduzir outros "fatores" explicativos do indivíduo ou do caso concreto, mas de reconstituir os "níveis" pelos quais o particular vive o universal (social e histórico) de modo específico. Outros elementos explicativos além do econômico não são "fatores", isto é, independentes entre si e talvez só exteriormente articulados; eles devem formar a "totalização" constantemente reiterada.

Como Sartre define, afinal, esta categoria? A “totalização" é um movimento "sintético", um método que admite a "multiplicidade hierárquica de significações" (SARTRE, 1986, p. 101)³. Não haveria uma única significação nos eventos históricos, e sim uma "multiplicidade", isso é claro. Só que a referência a uma "hierarquia" pode nos induzir ao erro de voltar aos esquemas dedutivos. Ao contrário disso, para Sartre ela não autoriza a reduzir as "significações" umas às outras, como fazem os marxistas: como a "significação mais geral serve de quadro para a mais concreta, (...) é impossível deduzi-la ou dissolvê-la" (SARTRE, 1986, p. 95); a relação entre as significações nos diferentes "níveis" de generalidade, então, é que as "mais gerais" compõem apenas um "quadro" mais amplo, e não que precedam logicamente as "mais concretas". Por isso, "é impossível separar estas (...) significações ou reduzi-las uma a outra: elas são faces inseparáveis de um mesmo objeto" (SARTRE, 1986, p. 101). Em primeiro lugar, a impossibilidade de "reduzir" umas às outras indica que 
elas "são irredutíveis", no sentido mesmo daquela "irredutibilidade de um certo real ao pensamento" mencionada antes como característica da crítica de Kierkegaard a Hegel: a significação mais concreta apresenta sempre um resíduo inapreensível pela "significação mais geral".

Por isso, em segundo lugar, a "inseparabilidade" dos níveis de significação obriga o pesquisador a apresentá-los simultaneamente; mais ainda, a reconstituir a sua imbricação revelando o modo específico pelo qual, como também já vimos antes, o particular vive o universal. Este ponto tem importância estratégica, merecendo análise mais detalhada.

Sartre pretende compreender as situações concretas em que os fenômenos particulares não são aparências ilusórias ou secundárias, mas são as formas únicas de manifestação do universal, o modo único de ele existir. Um personagem histórico "vive o universal como particular" (SARTRE, 1986, p. 57), como um "papel” desempenhado por um ator, conforme o revelador exemplo apresentado em Questões de Método, para explicar a relação entre a práxis imaginada e a real. $\mathrm{O}$ ator seria ao mesmo tempo ele mesmo e o papel que desempenha, e não apenas ele mesmo e só a parentemente o personagem, num tipo de essencialismo ao gosto de tantos marxistas. Em vez de dizer que se não tivesse aparecido Napoleão, por exemplo, outroteria feito o que ele fez, pois o importante seria o processo social que o engendrou, Sartre propõe a dialética, o jogo das mediações demonstrando "que Napoleão era necessário, que o desenvolvimento da Revolução forjou ao mesmo tempo a necessidade da ditadura e a personalidade inteira daquele que a devia exercer (...) em uma palavra, que não se trata de um universal abstrato, de uma situação tão mal definida que diversos Bonapartes teriam sido possíveis, mas de uma totalização concreta onde esta burguesia real, feita de homens reais e viventes, devia liquidar esta Revolução e onde esta R evolução criou seu próprio liquidador na pessoa de Bonaparte" (SARTRE, 1986, p. 78-79).

Neste texto, a totalização é qualificada de "concreta", retomando em parte o sentido hegeliano do "con-creto" recuperado por Marx, como a "síntese das múltiplas determinações" (MARX, 1983, p. 35), como o "con-crescere" - crescer junto numa determinação recíproca e dinâmica. Esta dialética é "concreta" porque enfatiza a necessidade das "mediações", em um jogo do particular e do universal no qual o particular não é simplesmente descartado como um acessório casual, apenas "possível", 


\section{4}

como teriam sido os "diversos Bonapartes". Ao reducionismo dos marxistas, seus contemporâneos, Sartre opõe a própria dialética, corretamente recuperada pelo conceito de "mediação", cunhado por Hegel para definir seu "método".

Estaria ele assim convocando um 'retorno a Hegel'? De certa forma. Pois ele se refere a esta filosofia como "a mais ampla totalização filosófica" (SARTRE, 1986, p. 13), ressaltando nela o movimento de dissolução contínua do Ser em si mesmo, a alienação e o retorno a si do homem: a cisão e a contradição "que fazem nossa infelicidade são momentos que se põem para ser ultrapassados (...) o puro vivido de uma experiência trágica, de um sofrimento que conduz à morte é absorvido pelo sistema como (...) uma passagem que conduz ao absoluto, o único concreto verdadeiro" (SARTRE, 1986, p. 14). Quanto à já mencionada crítica de Kierkegaard a Hegel, é interessante notar que Sartre concorda com ela só até certo ponto: "ao se colocar no quadro da época, Kierkegaard tem razão contra Hegel tanto quanto Hegel tem razão contra Kierkegaard. Hegel tem razão: em vez de se obstinar como o ideólogo dinamarquês em paradoxos rígidos e pobres que remetem finalmente a uma subjetividade vazia, é o concreto verdadeiro que o filósofo de Iena visa por seus conceitos, e a mediação se apresenta sempre como enriquecimento. Kierkegaard tem razão: a dor, a necessidade, a paixão, a pena dos homens são realidades brutas que não podem ser ultrapassadas nem modificadas pelo Saber" (SARTRE, 1986, p. 16). Se a realidade profunda do homem em sua vida trágica é de fato irredutível ao Saber, isso não invalida o esforço da dialética em "enriquecer” e dar conteúdo à subjetividade, que de outra forma seria "vazia". Ao retomar Hegel, Sart re busca "situar" (mais exatamente do que explicar) o singular do indivíduo e de sua ação, e com isso denunciar as pseudodialéticas que se restringem ao universal ou essencial, sem conseguir ou querer passar daí de volta ao particular ou existente. Essa é a função das mediações.

Aqui se esclarece mais o sentido do conceito de "vida", que tem a ver já em Hegel não só com o real vivido, mas com o movimento de transformação, de devir, do próprio real - Sartre fala de "totalidades vivas" (viventes - vivantes), pelo qual a dialética apreenderia "o movimento real de uma unidade no processo ('en train') de se fazer, e não o estudo (...) de uma unidade já feita" (SARTRE, 1986, p. 66). Esta "vida” afinal é a 
história, é a dinâmica do "con-creto" em que se imbricam os níveis de significação do vivido particular e do sentido universal. É preciso, então, "reconstituir o movimento sintético de uma ve rdade que veio a ser" (SARTRE, 1986, p. 24).

O interessante é que o existencialismo, portanto, é que teria a função de recuperar a própria dialética, soterrada pelo monismo dos marxistas, no qual os dois lados - acaso e universalidade - são absolutamente separados, sem relação um com o outro e, assim, “abstratos”. É o existencialismo que permitiria perceber que "assim, o marxismo vivo (vivente) é heurístico" (SARTRE, 1986, p. 29), ou seja, capaz de descobrir algo, de encontrar a "situação" particular no quadro geral. Isso é o que Sart re chama de "método progressivo-regressivo", que "leva em conta ao mesmo tempo a circularidade das condições materiais e o condicionamento mútuo das relações humanas estabelecidas sobre esta base" (SARTRE, 1986, p. 72).

Até aqui, contudo, vai o acordo com Hegel. Pois Kierkegaard também "tem razão", quando afirma o fenômeno humano como algo "irredutível" ao Saber, quando recusa a possibilidade de que as "realidades brutas (possam) ser ultrapassadas (ou) modificadas pelo Saber", conforme a citação anterior. Lembremos que o "ultrapassado (dépassê)" aqui remete diretamente ao famoso conceito da Aufhebung hegeliana - processo de simultânea conservação e negação. O particular, então, não pode ser simplesmente ultrapassado pelo universal, como ocorreria na dialética de Hegel, constituindo também esta sua "irredutibilidade" o conceito sartreano de "vida".

Distingue-se claramente nisso o sentido que Sartre confere à dialética. Ele quer uma "dialética flexível e paciente (...) que recuse considerar a priori que todos os conflitos vividos opõem contraditórios ou mesmo contrários: para nós, os interesses que estão em jogo podem não encontrar necessariamente uma mediação que os reconcilie" (SARTRE, 1986, p. 116). Ou seja, há conflitos em que os opostos não são contraditórios, o que depende do caso a ser considerado (a posteriori), depende de haver uma mediação que os "reconcilie" no sentido de estabelecer uma unidade, uma relação que os oponha como contraditórios. $\mathrm{O}$ conceito sartreano de "mediação" é de matriz hegeliana, mas o de "reconciliação" não. Bem como não o é a idéia de uma"não-necessidade" de que os 


\section{6}

interesses reais encontrem mediações, pois em Hegel toda a diferença necessariamente se configura como oposição em si contraditória.

Tratando dos interesses reais, Sart re continua: "Na maior parte do tempo, uns excluem os outros, mas o fato de que eles não podem ser satisfeitos ao mesmo tempo não prova necessariamente que sua realidade se reduz a uma pura contradição (...)" - ou seja, a exclusão recíproca não os limita a dois únicos opostos, numa unidade contraditória. O texto esclarece, na seqüência: "Claro, o capitalista possui os instrumentos de trabalho e o trabalhador não os possui: eis uma contradição pura. (...mas) o roubado não é o contrário de quem rouba, nem o explorado o contrário (ou contraditório) do explorador: explorador e explorado são homens em luta num sistema em que a raridade constitui o caráter principal.” (SARTRE, 1986, p. 116). A relação entre explorado e explorador não é necessariamente uma relação contraditória, ou entre contrários, pois ambos podem estar num ambiente de "raridade", de modo que sua luta se dissolve em outros elementos do sistema. Só o será se sua relação "encontrar a mediação que os reconcilie", isto é, oponha; esta é a relação oposta de ambos os contrários, e de um pelo outro, aos instrumentos de trabalho, que uns monopolizam para deles privar aos outros.

Em suma - e é assim que Sartre interp reta a crítica materialista de Marx ao idealismo de Hegel -, também a dialética não pode ser um método aplicado a priori aos fenômenos históricos. Nem todos os conflitos reais, entre "homens em luta", de fato os opõe no sentido estrito de uma contradição, propiciando uma leitura dialética. Numa concepção idealista, a dialética funcionaria como uma camisa de força retirando dos homens reais a sua liberdade.Além da dialética, portanto, o que o existencialismo restitui ao marxismo seria o próprio materialismo.

E materialismo entendido como a "irredutibilidade" de todo real ao Saber absoluto, o enquadramento de qualquer conflito na matriz da contradição, a dedução das significações "mais concretas" a partir das "mais gerais", a desaparição do evento ou do indivíduo singular no bojo de estruturas sociais todo-determinantes. Sartre lembra que "o homem alienado, mistificado, reificado etc., não é menos homem. E quando Marx fala da reificação, ele não quer mostrar que nós somos transformados em coisas, mas que somos homens condenados a viver humanamente a condição de coisas materiais" (SARTRE, 1986, p. 97, nota). Neste ponto 
a pa rece a importantíssima questão do "fetichismo", termo que também Sartre utiliza positivamente na sua crítica ao idealismo. Examinemos com algum detalhe também este ponto.

Entre as "mediações" reais assinaladas por Sartre está o grupo social, caracterizado justamente por sua "autonomia relativa e poder de mediação” (SARTRE, 1986, p. 64) entre um nível mais geral de sociabilidade (divisão do trabalho, forças produtivas e relações de produção) e o indivíduo, "situando-o" na família, na categoria profissional, no clube etc. Mas os marxistas desconheceriam esta mediação em toda a sua dimensão dialética , não percebendo que "não há senão homens e relações reais entre os homens" (SARTRE, 1986, p. 72). O próprio Marx "não está muito distante" (SARTRE, 1986, p. 73) desta idéia, mas teria se afastado dela um pouco, ao enfatizar às vezes exageradamente o caráter reificador do fetichismo. Isso, porém, não "permite concluir por uma insuficiência definitiva do método marxista, mas simplesmente por seu desenvolvimento insuficiente" (SARTRE, 1986, p. 70). Afinal, "a teoria do fetichismo, esboçada por Marx, jamais foi desenvolvida, e, de qualquer forma, ela não poderia se estender a todas as realidades sociais" (SARTRE, 1986, p. 73).

Empreendendo então este "desenvolvimento" do conceito, Sart re reconhece a força do "mercado, inicialmente simples complexo de relações humanas, tendendo a tornar-se mais real que os vendedors e que seus clientes", mas reprova o fato de que o marxismo "considera o mercado como uma coisa, e que suas inexoráveis leis contri buem para reificar as relações entre os homens" (SARTRE, 1986, p. 73). O problema é que, segundo ele, Marx faz "repentinamente (...) um passamoleque ('tour de passe-passe') dialético (e) nos mostra esta abstração monstruosa como o verdadeiro concreto (trata-se, é claro, de uma sociedade alienada), enquanto os indivíduos (por exemplo, o operário submetido às leis férreas do mercado de trabalho) caem por seu turno na abstração". A sua crítica fica então mais ácida: “a c reditamos ter retornado ao idealismo hegeliano. Pois a dependência do operário que vende sua força de trabalho não pode de forma alguma significar que o trabalhador caiu na existência abstrata. Ao contrário, a realidade do mercado, por mais inexoráveis que sejam suas leis, e até em sua aparência concreta, repousa sobre a realidade de indivíduos alienados e sobre sua separação" (SARTRE, 1986, p. 73-74). 
Do ponto de vista de Marx, esta objeção mereceria também alguns reparos importantes. A força que separa os indivíduos se autonomiza deles e os separa de modo distinto do qual eles são separados em outras formas sociais, isto é, o faz como força externa, coisificada, natural. Além disso, o lado da separação é dialeticamente dependente do da união: considerar só a separação seria algo unilateral.

Mas Sartre responde que o Fetichismo não decorre de uma coisificação, e sim de um conflito e conseqüente dépassement da ação de um indivíduo ou de um grupo pela de outro, criando um resultado que nem o primeiro nem o segundo visavam. Ele diz:"mas se a história me escapa, isto não decorre do fato de eu não a fazer: decorre de que o outro também a faz"; ou ainda, "o sentido objetivo do que eles fazem vai se impor a eles como uma existência real, na medida mesma em que a resistência do outro não lhes permite apreender sua atividade como pura e simples objetivação deles mesmos" (SARTRE, 1986, p. 82 e 118). Ou seja, dos antagonismos surge uma resultante que escapa a cada particular, constituindo o universal como uma "existência real", um "sentido objetivo". Mas a ação humana sempre está em primeiro plano. Por isso ele continua "não é verdade que a história nos apareça completamente como uma força estrangeira. Ela se faz cada dia pelas nossas mãos, mais do que acreditamos fazê-la (...) e contudo ela é menos opaca do que nunca: o proletariado descobriu e liberou o 'seu segredo'; o movimento do capital é consciente de si mesmo, tanto pelo conhecimento que os capitalistas tomam dele como pelo estudo que dele fazem os teóricos do movimento operário" (SARTRE, 1986, p. 84).

A este otimismo quanto à liberdade humana, pode-se objetar a famosa frase de Marx: "não o sabem, mas o fazem"; ou seja, é indiferente a descoberta ou a consciência dos agentes para a sua necessidade de continuar executando as operações econômicas capitalistas fetichizadas.

No entanto, o interessante é perceber na interpretação sartreana do fetichismo a sua leitura específica de Marx. Em primeiro lugar, a definição de "abstrato" e "concreto", justa no que se refere ao modo de exposição dialético, não recorre aqui ao conceito de trabalho abstrato, por não descrever o processo real/social de abstração realizado pelas trocas reiteradas no mercado. Em segundo lugar, se as "coisas fetichizadas" não podem ser abstrações, pois Sartre critica o tempo inteiro os marxistas que 
esquecem das mediações que dão carne às categorias universais abstratas (e quase sempre a "abstração" tem para ele este mau sentido), então elas são o que ele chama de "coletivos", como o mercado, e também a família, a cidade, o clube de leitura. Isto é, são grupos compostos de homens e por suas relações, pois nada mais existe. E assim Sartre dilui o fetiche nos "coletivos" que sempre existiram, ou seja, perde em parte a especificidade do capitalismo, embora o tempo inteiro lembre que "se trata de uma sociedade alienada, é claro".

Examinando sua definição de fetiche, como aparece no texto acima, percebemos que para Sartre ele resulta da alienação. E este conceito, por sua vez, é definido como "uma realidade histórica e perfeitamente irredutível a uma idéia" (SARTRE, 1986, p. 18), no mesmo espírito da crítica de Kierkegaard a Hegel. Se levarmos em conta o conceito de "abstração" tal como aparece no "trabalho abstrato", porém, o fetiche se revela como mais do que um "coletivo" de "indivíduos alienados": a abstração é um processo real do capitalismo que qualifica a mera alienação.

Também podemos examinar neste sentido o ponto fundamental da aproximação sartreana do marxismo ao existencialismo: a práxis. Os homens fazem sua história e são simultaneamente feitos por ela. $\mathrm{O}$ homem é " p roduto de seu produto, e ao mesmo tempo um agente histórico não pode, de forma alguma, passar por um produto" (SARTRE, 1986, p. 82). Em parte isso é verdade, na medida apenas em que o homem pode resgatar sua humanidade na práxis transformadora da realidade; mas não é verdade sempre, já que, na inversão fetichista, o homem está posto numa condição coisificada. Mas Sartre continua, "Os homens fazem sua história sobre a base de condições reais anteriores (...) mas são eles que a fazem e não as condições anteriores: de outro modo, eles seriam simples veículos de forças inumanas"; de fato, as condições não "vão sozinhas ao mercado", como diz Marx, mas forçam os homens a ir, impõem-se a eles, mesmo que eles o saibam e queiram delas escapar. Neste caso, o cotidiano quase sempiterno, eles agem movidos por "forças inumanas", sim.

Esta diluição do conceito forte de "fetiche", ao abrir o campo de possibilidades para a ação humana, por outro lado, ilumina um aspecto deixado à sombra por versões mais recentes do marxismo, a saber, a capacidade de transformação das chamadas "condições objetivas". Ao 
invés de soterrado ou sufocado pelo peso de um fetiche todo-poderoso, ou, ao contrário, de simplesmente livre para impor sua vontade, o homem aparece configurado fenomenologicamente, isto é, lançado em sua situação, determinado pela determinação do seu mundo e vice-versa. Depois de voltar à questão do papel do indivíduo na realização das forças sociais, agora citando e criticando o texto do velho Plekhanov, Sartre afirma:"Só que a questão não é essa: trata-se de determinar em que nível nos colocamos para definir a realidade" (SARTRE, 1986, p. 119).

Sem dúvida, é um aporte interessante para as teorias políticas que, inspiradas no marxismo, não conseguem se desenredar da alternativa ação subjetiva versus condições objetivas. Mas de certa maneira Sart re também se enreda nesta dificuldade, ao diluir o fetiche, isto é, as condições objetivas, para repor a ênfase sobre as possibilidades da ação humana. Pois com seu conceito de "humano" e de "ação", ele busca explicitamente o retorno à tradição humanista. A ação pensada como eficácia, pelos seus resultados práticos, como realização particular do universal; o homem pensado como a luta contra a alienação presente em toda a relação social, em todo o acontecimento: assim, a subjetividade retoma uma espessura diante do mundo que ameaça justamente o mais interessante de sua crítica ao marxismo, como vimos, a perspectiva fenomenológica da "situação".

A crítica de Sart re, portanto, mantém sua importância, apontando para a superação radical da aporia das teorias da ação inspiradas por Marx. Mas ela mesma não parece cumprir plenamente seu programa, recaindo em um conceito de "homem" que fica aquém de sua exigência. Resta fazer este último reparo. Mas ficam abertas, a partir daí, as possibilidades para tanto.

\footnotetext{
1 É nestes termos que Sartre se refere à filosofia de Marx em "Questões de Método", de 1960 (SARTRE, 1986, p. 12) e depois: "Ele permanece a filosofia de nosso tempo: ele não é ultrapassável, porque as circunstâncias que o engendraram ainda não foram ultrapassadas" (SARTRE, 1986, p. 32, n. 1).

2 “É preciso simplesmente rejeitar o apriorismo: só o exame sem preconceitos do objeto histórico poderá, em cada caso, determinar se a ação ou a obra refletem os móveis superestruturais de grupos ou indivíduos formados por certos condicionamentos de base ou se não se
}

doispontos, Curitiba, São Carlos, vol. 3, n. 2, p.159-171, outubro, 2006. 
pode explicá-los senão se referindo imediatamente às contradições econômicas e aos conflitos de interesse material" (SARTRE, 1986, pp. 42-43).

3 “As significações superpostas são isoladas e desmembradas pela análise. O movimento que as reúne na vida é, ao contrário, sintético.” (SARTRE, 1986, p. 101 e 95).

\section{Referências bibliográficas}

MARX, K. 1983. Grundrisse der Kritik der politischen Ökonomie. MEW

42. Berlin: Dietz Verlag

SARTRE, J.-P. 1986. Questions de Méthode. Paris: Gallimard.

doispontos, Curitiba, São Carlos, vol. 3, n. 2, p.159-171, outubro, 2006. 
172

O

○ 